\title{
Uma proposta de oficina baseada na BNCC com o jogo Planet Families
}

\author{
${ }^{1}$ Michael Monteiro Matos, ${ }^{2}$ Bruno Martins Siqueira, ${ }^{3}$ Érica Cupertino Gomes \\ 1, 2, 3 Universidade Federal do Tocantins (UFT)
}

Palavras-Chave: Base Nacional Curricular Comum (BNCC), Gamificação, Astronomia.

\section{Introdução}

Com a aprovação da Base Nacional Comum Curricular (BNCC) a implantação nas escolas ocorrerá até o ano de 2022, com isso, todos os professores terão que adaptar em seus planos de aula as habilidades e competências da BNCC. Ela tem como objetivo garantir aos jovens uma aprendizagem essencial, ela está organizada em quatro áreas de conhecimento, cada uma contando com as suas competências específicas, a cada uma das competências são relacionadas habilidades, que indicam as aprendizagens essenciais aos estudantes do Ensino Médio (BRASIL, 2018).

A proposta da criação dessa oficina tem como público alvo professor da educação básica, cujo objetivo é proporcionar a esses professores desenvolver com seus alunos uma prática no aprendizado utilizando novas tecnologias. A metodologia usada será a gamificada, com o game Planet Families, através das competências geral cinco e a habilidade EM13CNT204 das ciências da natureza e suas tecnologias do ensino médio da BNCC.

O jogo é uma ferramenta bastante utilizada no cotidiano e que proporciona não somente o entretenimento, mas também um aprendizado. Segundo Grübel; Bez (2006, p. 15) "o jogo pode ser um ótimo recurso didático ou estratégia de ensino para os educadores e também ser um rico instrumento para a construção de conhecimentos". Para tanto, é necessário que os jogos sejam bem elaborados e explorados de modo que o jogador possa adquirir conhecimentos e construir conceitos.

O Planet Families é um game com modelo físico real de sistema solare, onde os jogadores podem criar seu próprio sistema solar e monitorar as interações entre seus planetas e estrelas possibilitando incluir asteróides e cometas. Seu modo de uso utiliza apenas arrastar os astros para a tela principal e soltando-as no local desejado. Esse game é encontrado no seguinte link: http://www.scigames.org/

\section{Metodologia}

A oficina deverá ser distribuída em dois encontros, com duração de uma hora e trinta minutos, em um laboratório de informática reservado exclusivamente para essa atividade e com 10 computadores conectados à internet. Será selecionada uma turma de ensino médio, do primeiro ano, e jogaram o Planet Families. Irão ser organizados, em cada computador, de forma que fiquem em grupos. Logo após a organização serão apresentados o jogo e o objetivo desejado nessa atividade.

A primeira aula: os primeiros 20 minutos, o professor deve investigar, de forma oral, os conhecimentos prévios dos alunos sobre sistema solar. Será lançado o primeiro desafio no Planet Families, para que eles criem em 20 min um sistema solar com uma estrela e com todos os elementos que o game proporciona. Quando o sistema solar estiver em equilíbrio, terão 30 minutos para observar e escrever o comportamento dos do sistema solar criado. Logo após irão discutir entre os grupos os resultados das análises do que ocorreu em seu sistema solar.

A segunda aula: o professor colocará um novo desafio, da mesma forma do primeiro, agora os alunos terão 30 minutos para tentar criar sistemas solares em equilíbrio com duas, três ou mais estrelas utilizando todos os elementos. Em cada sistema eles terão que analisar e elaborar suas explicações entre as interações dos astros dentro do sistema solares criados. Logo após, irão discutir entre os grupos os resultados das análises do que se observou em seu sistema solar.

No final, o professor com alguns argumentos, provocará nos alunos as habilidades adquiridas através do game. Como por exemplo, se eles poderiam explicar, com base nas observações, se poderiam ter na mesma orbita mais de um planeta de tamanho igual ou diferente; Em um sistema

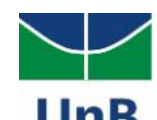


bi solar, poderia um planeta orbitar apenas em um sol; Estimular os alunos a buscar e elaborar argumentos de modelo que seja desconhecido, fazendo assim, os grupos tentem interagir buscando discutir o assunto e realizem suas previsões com argumentos adquiridos, com suas habilidades, de como seria esse modelo. Com isso, o professor discutirá algumas leis da física, como a lei das orbitas de Kepler e da lei da gravitação universal de Newton, proporcionando para 0 aluno, um aprendizado significativo.

\section{Resultados e Discussão}

Espera-se como resultados, que os alunos consigam adquirir as habilidades desejadas utilizando essa metodologia. E para isso, conforme as competências e habilidades da BNCC, o professor deverá avalia-los em conceitos, do quanto os alunos tiveram essas habilidades desenvolvidas nessa oficina. $O$ intuito é que o aluno consiga, por conta própria, desenvolver essas habilidades. Correspondendo as perguntas se o aluno: Conseguiu discutir e comunicar? Conseguiu analisar e elaborar argumentos? Cumpriu com determinados valores da escola?

\section{Conclusões}

Essa oficina pretende facilitar ao professor uma perspectiva de como utilizar novas tecnologias baseadas na BNCC. Mostrando uma metodologia em que o aluno é protagonista do próprio conhecimento. Referente à questão da motivação dos alunos, espera-se que o jogo consiga proporcionar um interesse maior em seus conhecimentos, comprovando assim, que 0 jogo pode contribuir de forma prazerosa, motivadora e eficaz auxiliando-os no crescimento cognitivo e aumentando o interesse pelo conteúdo. E para o professor, um auxílio e motivação, de como aplicar com metodologias com base nas competências e habilidades na BNCC.

\section{Agradecimentos}

À instituição Universidade Federal do Tocantins que proporcionou chegar a esse evento. À UnB com pelo evento do I Encontro Regional do MNPEF Centro-Oeste/Norte e à Capes pela bolsa de estudos.

\section{Referências}

BRASIL. Ministério da Educação. Base Nacional Comum Curricular (BNCC). Brasília: MEC, 2018. Disponível em:

http://basenacionalcomum.mec.gov.br/images/BNCC_EI_EF_110518_versaofinal_site.pdf Acesso em: 3 jun. 2019.

GRÜBEL, J. M.; BEZ, M. R. Jogos Educativos. Revista Novas Tecnologias. v. 4, n. 2, dezembro, 2006

KAPP, K. M. The gamification of learning and instruction: game-based methods and strategies for training and education. San Francisco: Pfeiffer, 2012.

PAULA, T. V.; SOUZA, E. V. P.; SILVA, D. M.; RIBEIRO, M. E. N. P. Proposta Educativa Utilizando o Jogo RPG Maker: Estratégia de Conscientização e de Aprendizagem da Qímica Ambiental. HOLOS, v. 8, 2015. 